Journal of Agriculture and Natural Resources (2018) 1(1): 114-121

ISSN: 2661-6270 (Print), ISSN: 2661-6289 (Online)

\title{
Research Article \\ Impacts of climate change on rice production and strategies for adaptation in Chitwan, Nepal
}

\author{
Sachin Gahatraj ${ }^{1}$, Ritesh Kumar Jha ${ }^{1}$ and Om Prakash Singh ${ }^{2}$ \\ ${ }^{1}$ Faculty of Agriculture, Agriculture and Forestry University, Chitwan, Nepal \\ ${ }^{2}$ Associate Professor, Department of Agricultural Extension and Rural Sociology, Agriculture and \\ Forestry University, Chitwan, Nepal \\ *Correspondence: sachingtj19@gmail.com; ORCID: https://orcid.org/0000-0002-6294-1733
}

Received: August 23; Accepted: December 3; Published: December 09.

(C) Copyright: Gahatraj et al. (2018).

(c) (1) This work is licensed under a Creative Commons Attribution-NonCommercial 4.0
International License.

\begin{abstract}
This study was conducted to understand perception of farmers about climate change; how it affects rice production and what are the local adaptation strategies adopted by farmers to maintain rice yield in Chitwan district of Nepal. A total of 90 rainy season rice farming household were surveyed with semi-structured interview schedule. The data obtained were analyzed using SPSS and MS Excel. Majority of the respondents $(91.20 \%)$ perceived deviation in weather parameters in last 10 years. Most of the farmers had perceived drought as the major impact of climate change and nursery stage of rice to be highly prone to climate impact. Higher proportion of farmers had experienced delay in transplanting and harvesting time of paddy in last 10 years. Many farmers had already replaced local varieties by either improved or hybrid rice variety resilient to climate change. Increased insects infestation and weed menace along with outbreak of new types were found to be major production problem perceived by farmers at study area. Most of the respondents $(50 \%)$ were expecting technical supports followed by infrastructure development (20.6\%) from different organizations. Climate resilient projects and programs designed in bottom up approach to enhance understanding of impacts of climate change will help farmers to cope climate risk on rice production.
\end{abstract}

Keywords: Climate Change, Perception, Adaptation, Rice, Yield

Correct citation: Gahatraj, S., Jha R.K. \& Singh, O.P. (2018). Impacts of climate change on rice production and strategies for adaptation in Chitwan, Nepal. Journal of Agriculture and Natural Resources, 1(1), 114-121. 
Journal of Agriculture and Natural Resources (2018) 1(1): 114-121

ISSN: 2661-6270 (Print), ISSN: 2661-6289 (Online)

\section{INTRODUCTION}

The evidences of impact of climate change on crop production have drawn immense attention over the last decades (Tao et al., 2008). In Nepal, rice (Oryza sativa L.) is the most important staple crop which occupies $42.5 \%$ of total area under food grains and share about $51.6 \%$ on total grains production (ABPSD, 2016). Moreover, rice solely contributes $20 \%$ of agriculture GDP (CDD, 2015). Agro-ecology is highly vulnerable to climate change; however, many farmers are obscure about impact of climate change in rice production and adaptation strategies suitable on local context. Clear understanding of relationship between climate and crop yield is indispensible to identify potential impacts of climate change and to develop adaptation strategies to maintain rice yield (Lobell \& Field, 2007).

Climate change has different forms of impacts on rice. In 2006, drought in Eastern region of Nepal reduced yield by 30\%, while heavy flooding in Mid-Western and Far Western regions destroyed rice in field (Malla, 2008). The occurrence of drought is likely to affect rice production in Nepal as most of the area under rice production lack irrigation facility. The variation in spatial and temporal rainfall patterns negatively affected the summer rice crop in Nepal, particularly crops that are $100 \%$ dependent on rainfall for irrigation (Kharel et al., 2018; Regmi, 2007). Although developing countries like Nepal don't contribute significantly to global warming, these countries are more vulnerable to impact of climate change because of poor resiliency and coping capacity (Huq et al., 2004). Malla (2008) described some evidences of impacts of climate changes in Nepalese agriculture: decreased rice production by $30 \%$ in 2006 in eastern terai due to the drought, increase in number of dry days, increase in evapo-transpiration and reduce moisture availability in Mid western Terai, increase nitrogen content of rice by $16.3 \%$ due to rise in temperature but decreased by $9.8 \%$ due to the doubling of $\mathrm{CO}_{2}$.

Understanding farmers' perception and traditional beliefs about climate change may not coincide with reality but can be benchmark for development of farmers' friendly technologies and adaptation strategies to cope impacts of climate change. Adjustments taken to manage the losses or taking advantages of opportunities put forwarded by climate change are adaptations (Khanal \& Kattel, 2017). Many studies to understand perception of farmer about climate change and impacts in crop production have already been done globally. Although perception may not be dovetailed with reality, these can be considered to address challenges (Kusakari et al., 2014).

\section{METHODOLOGY}

\section{Survey Design and Study Area}

Chitwan district was selected to study the farmers-perceived impacts of climate change on rice production and locally adopted adaptation strategies to maintain rice yield in Terai region of Nepal. A total of 90 rice growing households were selected to study: 30 from Madi Municipality, 30 from Khairhani Municipality, and 30 from Ratnanagar Municipality. Semi-structured questionnaires were used to collect primary data regarding farmers' perceived changes in climate 
Journal of Agriculture and Natural Resources (2018) 1(1): 114-121

ISSN: 2661-6270 (Print), ISSN: 2661-6289 (Online)

parameters and adaptation strategies. Primary data were supplemented with Key Informant Interview (KII). Survey was conducted during October-November 2017.

\section{Statistical Analysis}

Data were entered and analysed using SPSS (Version-16.0) and MS Excel 2013.

\section{RESULTS AND DISCUSSION}

\section{Farmers' Perception about Climate Change}

Majority of the households $(91.20 \%)$ interviewed had observed deviation in weather parameters in the last 10 years. Most of the respondents $(82.4 \%)$ were obscure about climate change knowledge. For the highest proportion of farmers (47\%), the source knowledge about climate change and its impact on rice production was self experience followed by broadcasting media (44\%) (Figure 1). The highest proportion of farmers (38\%) in Chitwan perceived drought as the most serious problem followed by unpredicting flooding (32\%) (Figure 2). Majority of respondents $(91.2 \%)$ had perceived increase in summer temperature. Most of the farmers $(86.67 \%)$ perceived decreased source of water recharge, while $13.33 \%$ of the farmers did not feel any change. Majority of respondents perceived decrease in rainfall parameters and increase in drought parameters (Figure 3). MoE 2010, also reported the decreasing trend of rainfall and increasing drought duration.

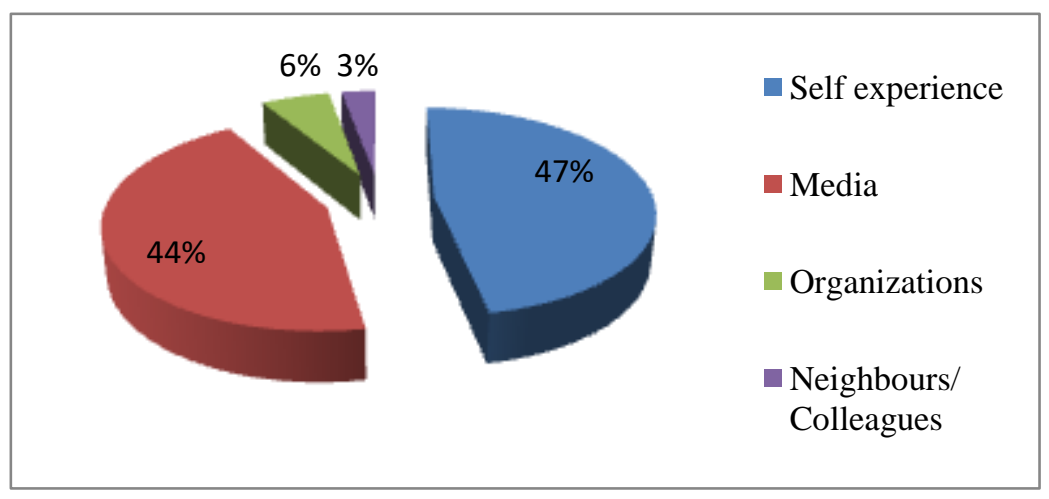

Figure 1. Source of knowledge about climate change and its impact on rice production 
Journal of Agriculture and Natural Resources (2018) 1(1): 114-121 ISSN: 2661-6270 (Print), ISSN: 2661-6289 (Online)

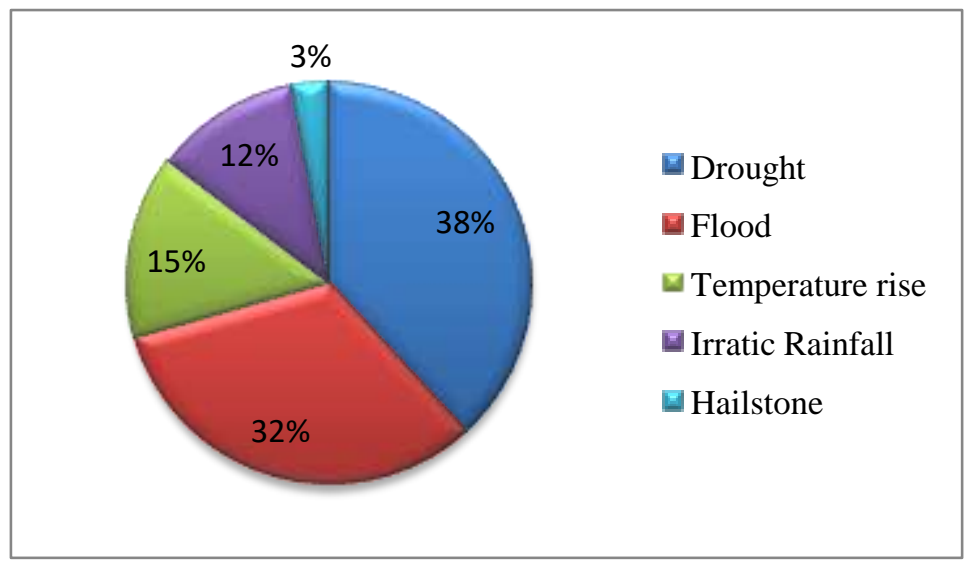

Figure 2. Major impacts of climate change perceived by farmers

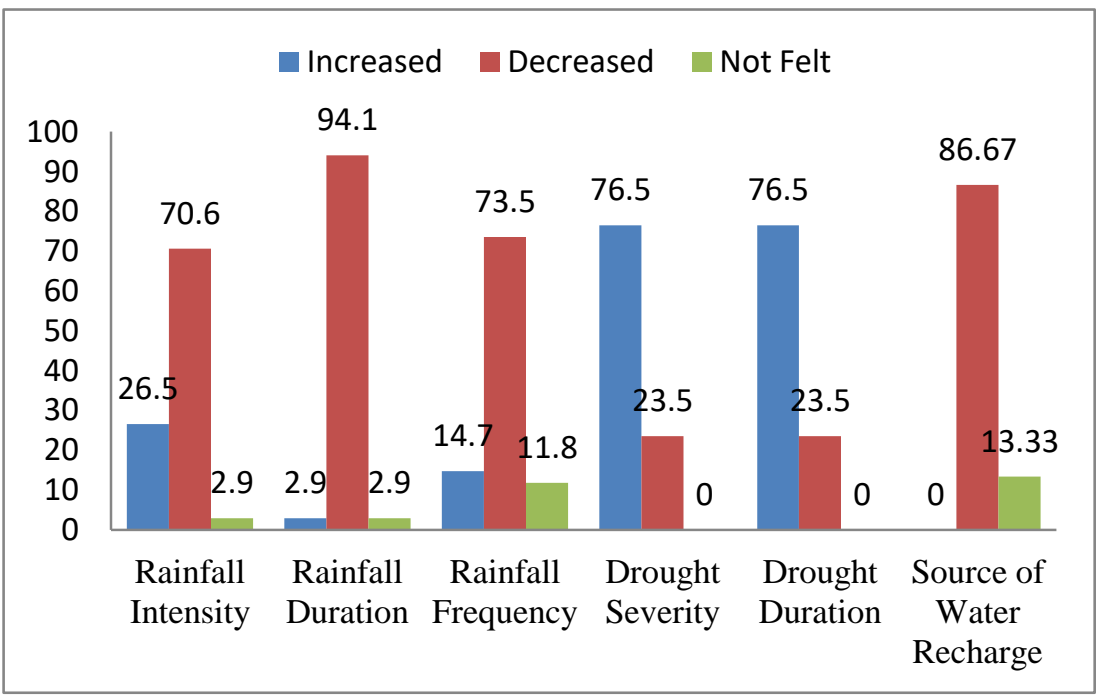

Figure 3. Farmers' perception about microclimate of study area

\section{Farmers' Perception about Impact of Climate Change on Rice Production}

Among the four growth phases of rice, the highest proportion of farmers $(38.20 \%)$ perceived seedling stage as the most prone phase of rice growth to impact of climate change which was followed by ripening stage (26.5\%) (Figure 4). Karn (2014) reported that rice in day time maximum temperature beyond threshold of 29.09 degree celsius during ripening phase leads to decline in rice productivity. During 1999 to 2008, average maximum day temperature was beyond threshold (Karn, 2014). Delay in rice transplanting had experienced by $88.2 \%$. Similarly, $64.7 \%$ farmers had experienced delay in harvesting as well. 
Journal of Agriculture and Natural Resources (2018) 1(1): 114-121 ISSN: 2661-6270 (Print), ISSN: 2661-6289 (Online)

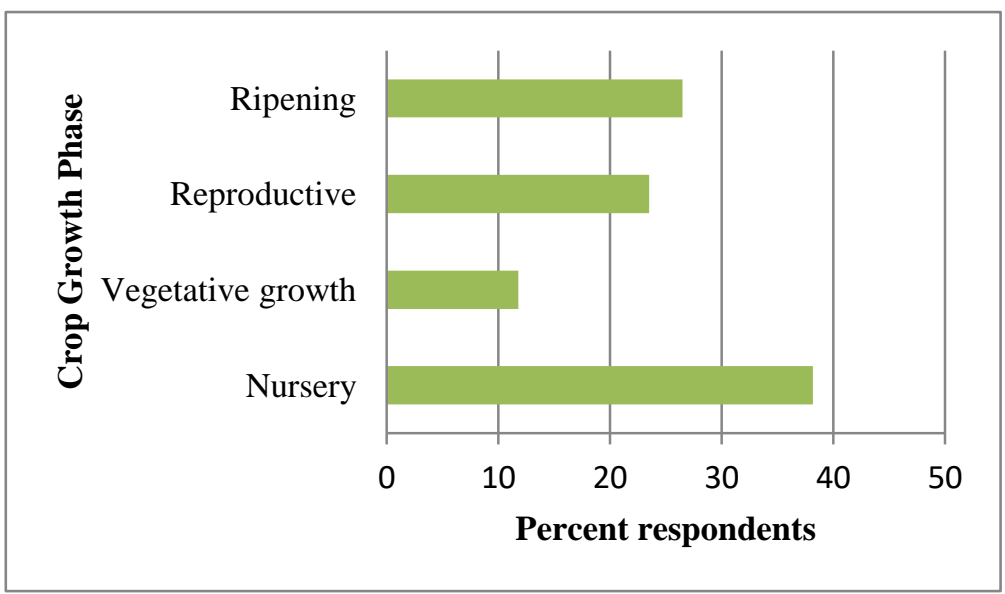

Figure 4. Rice growth phase most affected by climate change perceived by farmers

Majority of farmers $(71.76 \%)$ perceived increase in yield of rice, while $16.67 \%$ perceived constant yield of rice. This might be because all the farmers in Chitwan had replaced local varieties with either hybrid (Gorakhnath, US-312) or improved varieties (Sabitri, Ramdhan) (Khanal \& Kattel, 2017). Increase in yield might also be because of positive effect of carbon dioxide and temperature (Malla, 2008).

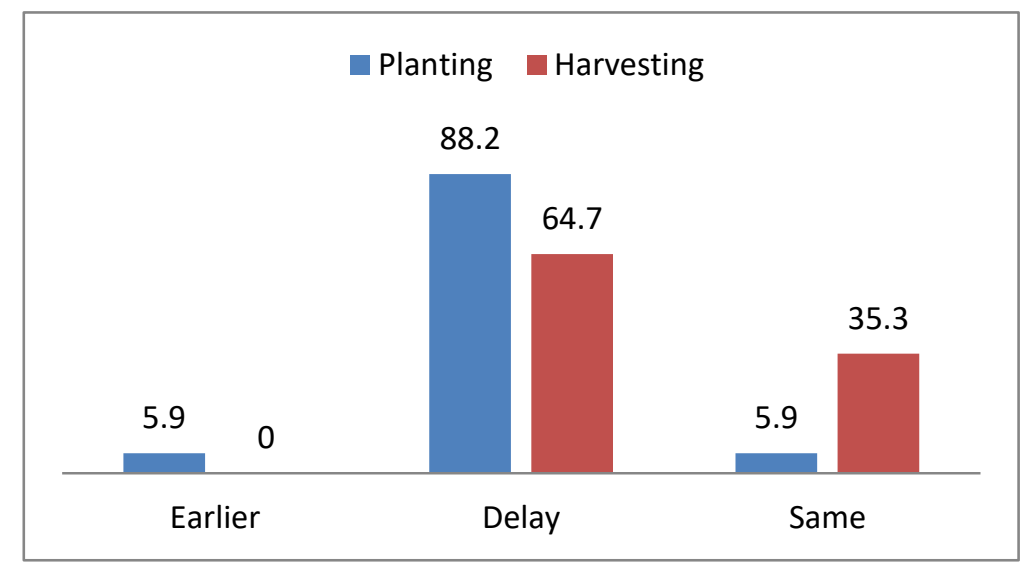

Figure 5. Shift in rice planting and harvesting time perceived by farmers

Delay in rice transplanting time might be due to delay in ample rainfall as $65 \%$ of cultivated land is rainfed. Similarly, delay in harvesting occurred. It subsequently causes decline in wheat production because of delay in wheat sowing in rice-wheat cropping system of Terai region of Nepal. Most of the respondents $(79.4 \%)$ had perceived increase in inset infestation in rice, while $20.6 \%$ noticed outbreak of new insect type in last 10 years. Similarly, it was found that $70.6 \%$ respondent perceived increase in weed menace and $20.6 \%$ noticed appearance of new types of weed in rice field. 


\section{Strategies for Adaptation}

Farming system was found to be changed as an adaptation strategy to impact of climate change on rice production in study area. Change in farming system involved change in planting time (67.6\%), change in rice variety (17.6\%), crop type (2.9\%), land use type (5.9\%) and change in command area under rice (5.9\%). Most of the farmers (76.67\%) had adapted either hybrid or improved rice varieties more resilient to climate impact they were facing. Most of the farmers (76\%) weren't using any insecticides, while 15\% used chemical, 6\% used organic and 3\% used both types of insecticides. Only $2.9 \%$ farmers had already done rice insurance and $14.7 \%$ are willing to do, while $82.4 \%$ are still reluctant regarding crop insurance. With no any aids in vulnerable region, farmers have to face an unpropitious task: maintaining and accreting rice yield. There is always expectation where is paucity frustrating development. To maintain and increase rice yield, farmers were expecting technical supports (50\%), infrastructure development (20.6\%), training campaign (11.6\%), crop insurance scheme (8.8\%) and financial support (8.8\%) from different organizations.
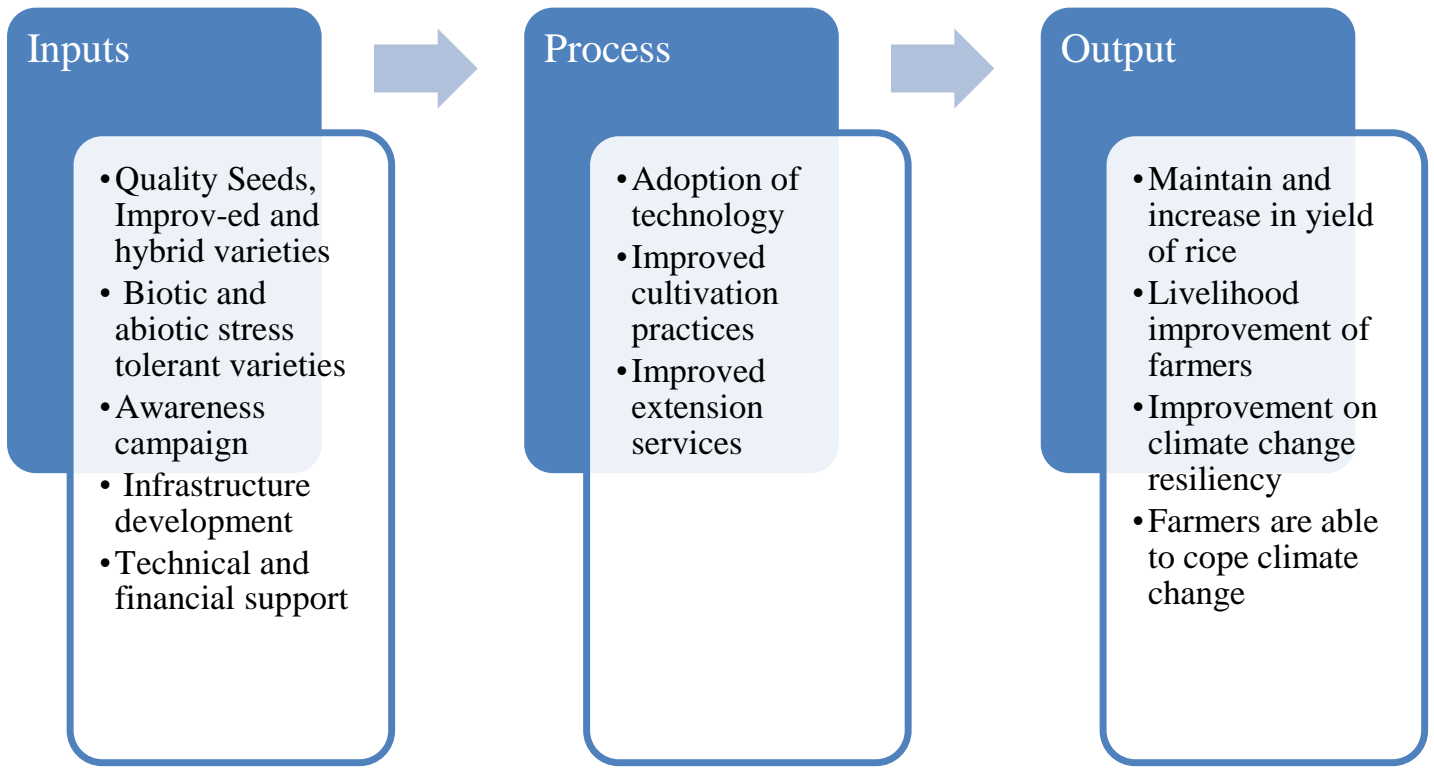

Figure 6. Log framework (Source: Field Survey, 2017)

\section{CONCLUSION}

This study figured out farmers-perceived impacts of climate change on rice production and adaptation strategies undertaken to maintain rice yield based on household survey. Climatic parameters were found to be deviated from last 10 years in study area. So, farmers were adapting different adaptation strategies to minimize yield loss or maintain yield of rice. Farmers' perception along with traditional beliefs should be considered while making policies, developing 
Journal of Agriculture and Natural Resources (2018) 1(1): 114-121

ISSN: 2661-6270 (Print), ISSN: 2661-6289 (Online)

technologies and designing projects to help farmers to adapt climate change. Policies and projects should be designed to enhance farmers' knowledge about climate change and impacts in agro-ecosystem. Bottom up approach will be more effective to disseminate the adaptation strategies among farmers.

\section{ACKNOWLEDGEMENTS}

The authors are profoundly grateful to all the respondents of Chitwan districts of Nepal. They are indebted to Dr. Om Prakash Singh, Associate Professor, Department of Agricultural Extension and Rural Sociology, Agriculture and Forestry University, Chitwan, Nepal for his mentorship and unstinting productive suggestions during study. They are also indebted to all the helping hands during study.

\section{Author Contributions}

S.G and R.K.J designed and performed experiments; O.P.S developed methodology and amended questionnaire; S.G and R.K.J collected data; S.G analyzed data, interpreted and wrote the manuscript; O.P.S reviewed manuscript for final publication

\section{Conflicts of Interest}

The authors declare that there are no conflicts of interest.

\section{REFERENCES}

ABPSD. (2016). Statistical information on Nepalese agriculture. Agribusiness promotion and statistic division, Agriculture Statistic Section. Singha Durbar, Kathmandu, Nepal: Government of Nepal,.

CDD. (2015). Rice varietal mapping in Nepal: Implication for development and adoption. Hariharbhawan, Nepal: Crop Development Directorate, Department of Agriculture.

Huq, S., Rahman, A., Konate, M., Sokona, Y., \& Reid, H. (2004). Mainstreaming adaptation to climate change in Least Developed Countries (LDCs). Climate Policy, 4(1), 25-43.

Karn, P. K. (2014). The impact of climate change on rice production in Nepal. South Asian Network for Development and Environemental Economics (SANDEE), Working PaperNo. 85-14.

Khanal, S., \& Kattel, R. R. (2017). Understanding Farmers' Perceptions and Adaptations to Climate Change and Variability in Rice Production at the Kaski and Chitwan Districts ,Nepal. Asian Research Journal of Agriculture , 2, 1-12.

Kharel, L., Ghimire, S. K., Shrestha, J. , Kunwar, C. B., \& Sharma, S. (2018). Evaluation of rice genotypes for its response to added fertility levels and induced drought tolerance during reproductive phase. Journal of AgriSearch, 5(1), 13-18.

Kusakari, Y., Kusakari, K. O., Jasaw, G. S., Dayour, F., Dzivenu, T., Lolog, V., et al. (2014). Farmer-perceived effects of climate changes on livelihoods in Wa west district, upper west region of Ghana. Journal of Disaster Research , 9, 516-528. 
Journal of Agriculture and Natural Resources (2018) 1(1): 114-121

ISSN: 2661-6270 (Print), ISSN: 2661-6289 (Online)

Lobell, D. B., \& Field, C. B. (2007). Global scale climate-crop yield relationship znc the impacts of recent warming. Environmental Researc Letters , 2.

Malla, G. (2008). Climate change and it's impact on Nepalese agricultre. The Journal of Agriculture and Environment, 9, 62-71.

MoE. (2010). National Adaptation Programme of Action (NAPA). Government of Nepal, Ministry of Environment, Singha Darbar, Kathmandu.

Regmi, H. R. (2007). Effect of unusual weather on cereal crops production and household food security. The Journal of Agriculture and Environment, 43, 20-29.

Tao, F., Yokozawa, M., Liu, J., \& Zhang, Z. (2008). Climate-crop yield relationship at provincial scale in China and the impact of recent climate trends. Climate Research, 38, 83-94. 